University of Nebraska - Lincoln

DigitalCommons@University of Nebraska - Lincoln

\title{
Efficacy of Pyriproxyfen for Control of Stored-Product Psocids (Psocoptera) on Concrete Surfaces
}

Christos G. Athanassiou

University of Thessaly, athanassiou@agr.uth.gr

Frank H. Arthur

USDA-ARS, frank.arthur@ars.usda.gov

Nickolas G. Kavallieratos

Benaki Phytopathological Institute

James E. Throne

USDA-ARS, Manhattan, KS, james.throne@ars.usda.gov

Follow this and additional works at: https://digitalcommons.unl.edu/usdaarsfacpub

Athanassiou, Christos G.; Arthur, Frank H.; Kavallieratos, Nickolas G.; and Throne, James E., "Efficacy of Pyriproxyfen for Control of Stored-Product Psocids (Psocoptera) on Concrete Surfaces" (2011). Publications from USDA-ARS / UNL Faculty. 2031.

https://digitalcommons.unl.edu/usdaarsfacpub/2031

This Article is brought to you for free and open access by the U.S. Department of Agriculture: Agricultural Research Service, Lincoln, Nebraska at DigitalCommons@University of Nebraska - Lincoln. It has been accepted for inclusion in Publications from USDA-ARS / UNL Faculty by an authorized administrator of DigitalCommons@University of Nebraska - Lincoln. 


\title{
Efficacy of Pyriproxyfen for Control of Stored-Product Psocids (Psocoptera) on Concrete Surfaces
}

\author{
CHRISTOS G. ATHANASSIOU,${ }^{1,2,3}$ FRANK H. ARTHUR, ${ }^{2}$ NICKOLAS G. KAVALLIERATOS, ${ }^{4}$ \\ AND JAMES E. THRONE ${ }^{2}$
}

\begin{abstract}
J. Econ. Entomol. 104(5): 1765-1769 (2011); DOI: http://dx.doi.org/10.1603/EC10424
ABSTRACT The insect growth regulator pyriproxyfen was evaluated as a surface treatment for control of three stored-product psocid pests Liposcelis bostrychophila Badonnel, Liposcelis decolor (Pearman), and Liposcelis paeta Pearman (Psocoptera: Liposcelididae). Nymphs were exposed for $35 \mathrm{~d}$ on a concrete surface treated with $2.3 \mathrm{mg}$ of active ingredient $/ \mathrm{m}^{2}$ pyriproxyfen. Exposure to pyriproxyfen significantly reduced the numbers of both adults and nymphs in comparison with untreated controls. In adults, the greatest reduction $(>90 \%)$ was for L. decolor and L. bostrychophila, whereas for L. paeta it was $49 \%$. Few adults of any species were found in the pyriproxyfen treatments. The greatest numbers of nymphs were recorded for L. bostrychophila for both pyriproxyfen treatments and controls. Few adults of any species were found in the pyriproxyfen treatments. The results indicate that pyriproxyfen is effective for control of $L$. bostrychophila, $L$. decolor, and L. paeta on concrete, and although complete control was not achieved, the results warrant further long-term study to determine whether pyriproxyfen can completely eliminate psocid populations over time.
\end{abstract}

KEY WORDS pyriproxyfen, insect growth regulator, Liposcelis, surface treatment, Psocoptera

Stored-product psocids (Psocoptera) belonging to the genus Liposcelis are important emerging pests of stored products. They feed on a wide variety of foods, but they are particularly associated with amylaceous commodities, such as grain and flour (Nayak 2006, Throne et al. 2006). One of the most important characteristics of these psocids is their high tolerance to many of the insecticides currently used for control of stored-product beetles (Nayak et al. 1998). Moreover, the bacterium-derived grain protectant spinosad was found to be ineffective against several Liposcelis spp. (Nayak et al. 2005, Athanassiou et al. 2009). Several organophosphate, carbamate, and pyrethroid insecticides have been evaluated for control of stored-product psocids on concrete surfaces, but they failed to provide long-term protection (Collins et al. 2000; Nayak et al. 2002a,b, 2003).

\footnotetext{
Mention of trade names or commercial products in this publication is solely for the purpose of providing specific information and does not imply recommendation or endorsement by the U.S. Department of Agriculture, the University of Thessaly or the Benaki Phytopathological Institute.

${ }^{1}$ Laboratory of Entomology and Agricultural Zoology, Department of Agriculture, Crop Production and Rural Development, University of Thessaly, Phytokou str., 38446, Nea Ionia Magnissia, Greece.

2 USDA-ARS, Center for Grain and Animal Health Research, 1515 College Ave., Manhattan KS 66502-2736.

${ }^{3}$ Corresponding author, e-mail: athanassiou@agr.uth.gr.

${ }^{4}$ Laboratory of Agricultural Entomology, Department of Entomology and Agricultural Zoology, Benaki Phytopathological Institute, 8 Stefanou Delta str., 14561, Kifissia, Attica, Greece.
}

Insecticides that are registered to control storedproduct beetles should be evaluated because of the increasing pest status of psocids. One such insecticide is the newly registered insect growth regulator (IGR) pyriproxyfen, which is labeled for use as a surface or spot treatment in food facilities in the United States. Several studies have documented its high efficacy against stored-product insect pests. Arthur et al. (2009) reported that pyriproxyfen was superior to hydroprene for control of several insect pests on wood, metal, and concrete surfaces, with a considerable level of persistence. Kostyukovsky et al. (2000) reported that pyriproxyfen was able to control pirimiphos-methyl-resistant Tribolium castaneum (Herbst) (Coleoptera: Tenebrionidae) populations and that it was superior to methoprene for control of the rice weevil, Sitophilus oryzae (L.) (Coleoptera: Curculionidae), and the lesser grain borer, Rhyzopertha dominica (F.) (Coleoptera: Bostrychidae). Hubert et al. (2007) found that a combination of permethrin + benzyl benzoate + pyriproxyfen was superior to chlorpyriphos, deltamethrin, beta-cyfluthrin, and a combination of deltamethrin + bioallethrin for control of several stored-product mites. However, there are no data available on efficacy of pyriproxyfen for control of stored-product psocids. The objective of our study was to determine whether pyriproxyfen applied at the label rate would be an effective surface treatment for control of psocids. 
Table 1. Numbers of adults and nymphs in control and pyriproxyfen-treated arenas (individuals/arena \pm SE) $35 \mathrm{~d}$ after application for each psocid species

\begin{tabular}{|c|c|c|c|c|c|c|}
\hline \multirow{2}{*}{ Treatment } & \multicolumn{2}{|c|}{ L. decolor } & \multicolumn{2}{|c|}{ L. paeta } & \multicolumn{2}{|c|}{ L. bostrychophila } \\
\hline & Adults & $\overline{\text { Nymphs }}$ & Adults & $\overline{\text { Nymphs }}$ & Adults & Nymphs \\
\hline Control & $9.4 \pm 1.0 \mathrm{a}$ & $6.9 \pm 1.5 \mathrm{a}$ & $3.9 \pm 0.7 \mathrm{a}$ & $4.7 \pm 1.7 \mathrm{a}$ & $8.5 \pm 0.3 \mathrm{a}$ & $60.1 \pm 5.3 \mathrm{a}$ \\
\hline Pyriproxyfen & $0.9 \pm 0.2 b$ & $2.9 \pm 1.2 b$ & $2.0 \pm 0.4 \mathrm{~b}$ & $0.9 \pm 0.6 \mathrm{~b}$ & $0.6 \pm 0.3 \mathrm{~b}$ & $11.1 \pm 4.2 \mathrm{~b}$ \\
\hline$t$ & -8.3 & -2.1 & -2.6 & -2.1 & -18.5 & -7.3 \\
\hline$P$ & $<0.01$ & 0.02 & 0.01 & 0.02 & $<0.01$ & $<0.01$ \\
\hline
\end{tabular}

Within each column, means followed by the same letter are not significantly different $(\mathrm{df}=70$; two-tailed $t$-test $)$.

\section{Materials and Methods}

Insects. Young nymphs $\left(\mathrm{N}_{1}-\mathrm{N}_{2}\right)$ of the psocids $L i$ poscelis bostrychophila Badonnel, Liposcelis decolor (Pearman), and Liposcelis paeta Pearman (Psocoptera: Liposcelididae) were used in the tests. L. bostrychophila generally is parthenogenetic (males have only recently been discovered; Mockford and Krushelnycky 2008), whereas the other two species reproduce after mating. Psocids were reared on a mixture of $97 \%$ cracked wheat kernels, $2 \%$ crisp rice, and $1 \%$ brewer's yeast at $30^{\circ} \mathrm{C}$ and $70 \% \mathrm{RH}$. To obtain individuals of standardized age for experiments, 30 female adults were left to oviposit in $35-\mathrm{mm}$ petri dishes containing red-colored psocid diet for $3 \mathrm{~d}$, and then the females were removed.

After an additional $7 \mathrm{~d}$, the newly emerged nymphs were removed with a fine brush (Opit and Throne 2008). The colored diet was prepared by mixing $100 \mathrm{~g}$ of crisp rice with a solution of $5 \mathrm{ml}$ of red food dye (Global ChemSources, Inc., Cedar Grove, NJ) in 300 $\mathrm{ml}$ of water. Afterward, the mixture was dried in a mechanical convection oven (HTM 85, Precision Scientific, Inc., Chicago, IL) for $2 \mathrm{~d}$, and then the dried mixture that resulted was grinded in a Wiley Mill by using a \#20 sieve (0.85-mm openings; Scientific Apparatus, Philadelphia, PA).

Insecticide. A formulation of pyriproxyfen ( $\mathrm{Ny}$ Guard, McLaughlin Gormley King [MGK] Company, Minneapolis, MN) that contains $10 \%$ active ingredient (AI) was used in the experiments at the label rate of $2.3 \mathrm{mg}(\mathrm{AI}) / \mathrm{m}^{2}$.

Bioassays. All tests were conducted in petri dishes ( $9 \mathrm{~cm}$ in diameter by $1.5 \mathrm{~cm}$ in height), which had a surface area of $\approx 62 \mathrm{~cm}^{2}$. The bottoms of the dishes were covered with driveway patching material (Rockite, Hartline Products Co., Inc., Cleveland, $\mathrm{OH})$ to create the concrete surface (hereby referred to as arenas). The arenas were prepared 1-2 $\mathrm{d}$ before the tests. The internal sides of the arenas were coated with Fluon (polytetrafluoroethylene, Northern Products, Woonsocket, RI) to prevent escape of psocids. The solutions of pyriproxyfen were prepared with distilled water. Dishes were sprayed with a Badger 100 artist's airbrush (Badger Corporation, Franklin Park, IL) to treat each individual concrete arena with $0.25 \mathrm{ml}$ of formulated solution per $62 \mathrm{~cm}^{2}$ area of the arena, which is equivalent to the label spray rate $3.8 \mathrm{l} / 94 \mathrm{~m}^{2}$. Twenty-four arenas were prepared for each psocid species: 12 were sprayed with pyriproxyfen, and 12 were sprayed with water as untreated controls. Ten psocids and five kernels of cracked wheat were placed on each arena, either before or after spraying. The 24 arenas were divided into four categories (six replicate dishes per category): 1) arenas that contained psocids before spraying, with the kernels added after spraying; 2 ) arenas that contained psocids and kernels before spraying; 3 ) arenas that did not contain psocids before spraying (the psocids were added immediately after spraying) but contained five cracked kernels of wheat; and 4) arenas that did not contain psocids or kernels before spraying (the psocids and the kernels were added immediately after spraying).

This procedure was replicated three times, with new arenas each time ( 3 by $24=72$ dishes for each species). After spraying, all arenas were placed in black plastic boxes containing saturated sodium chloride solution below a false floor to maintain the relative humidity at $\approx 75 \%$. The boxes were placed in incubators maintained at $30^{\circ} \mathrm{C}$ and $70 \% \mathrm{RH}$. All arenas were checked after $35 \mathrm{~d}$ of exposure, and the numbers of adults and nymphs were recorded separately for each arena.

Data Analysis. For each species, the numbers of adults and nymphs in the treated concrete arenas were compared with those in the respective control dishes using a two-tailed $t$-test with $n$ - $2 \mathrm{df}$ to indicate whether pyriproxyfen affected the number of psocids. Then, for each species and life stage, the data from the pyriproxyfen-treated dishes were analyzed using a one-way analysis of variance (ANOVA) to determine differences in number of psocids among the four treatment categories with JMP software (Sall et al. 2001). Means were separated by the honestly significant difference (HSD) test at $\alpha=0.05$ (Sokal and Rohlf 1995) .

\section{Results}

Adults. Numbers of adults were significantly reduced for all species in the pyriproxyfen-treated arenas compared with the numbers of adults in the controls (Table 1$)$. The greatest reduction $(>90 \%)$ was for L. decolor and L. bostrychophila. For these species, less than one adult per arena was recorded. The number of L. paeta adults was reduced by only $49 \%$. Significantly more $L$. decolor adults were recorded in arenas in which the kernels were treated first and the nymphs added afterward in comparison with the arenas in which the psocids were treated first and the 
Table 2. Numbers of $L$. decolor adults and nymphs in pyriproxyfen-treated arenas (individuals/arena $\pm \mathrm{SE}$ ) $35 \mathrm{~d}$ after spraying

\begin{tabular}{llc}
\hline \multicolumn{1}{c}{ Treatment } & Adults & Nymphs \\
\hline Without psocids, without kernels & $0.8 \pm 0.3 \mathrm{ab}$ & $0.2 \pm 0.1 \mathrm{a}$ \\
Without psocids, with kernels & $2.1 \pm 0.8 \mathrm{~b}$ & $9.4 \pm 4.2 \mathrm{~b}$ \\
With psocids, without kernels & $0.4 \pm 0.2 \mathrm{a}$ & $1.2 \pm 0.6 \mathrm{a}$ \\
With psocids, with kernels & $0.3 \pm 0.2 \mathrm{a}$ & $0.6 \pm 0.4 \mathrm{a}$ \\
$F$ & 4.1 & 4.2 \\
$P$ & 0.01 & 0.01 \\
\hline
\end{tabular}

Within each column, means followed by the same letter are not significantly different ( $\mathrm{df}=3,32$; HSD test at 0.05 ; "without" or "with" indicate absence or presence during spraying, respectively).

kernels added afterward or with arenas which contained psocids and kernels before spraying (Table 2). For L. paeta and L. bostrychophila, significantly higher numbers of adults were in arenas that did not contain psocids or kernels before spraying in comparison with the arenas in which the kernels were treated first and the psocids added afterward or vice versa (Tables 3 and 4).

Nymphs. The numbers of nymphs in the controls were significantly greater than the numbers of nymphs in the pyriproxyfen-treated dishes (Table 1). For both pyriproxyfen-treated and control arenas, the greatest number of nymphs was recorded for L. bostrychophila. Significantly more $L$. decolor nymphs were recorded in arenas that contained only kernels before spraying, in comparison with other treatments (Table 2). In contrast, no significant differences were noted in numbers of $L$. paeta nymphs among the four treatments (Table 3), and nymphs were found only in arenas that contained psocids and kernels before spraying. Significantly more L. bostrychophila nymphs were in arenas that did not contain psocids or kernels before spraying in comparison with the arenas in which the kernels were treated first and the psocids added afterwards or vice versa (Table 4 ).

\section{Discussion}

This is the first study in which the IGR pyriproxyfen was evaluated on concrete surfaces for control of stored-product psocids, and this is also one of the few studies that examined this insecticide for control of stored-product insects in general. Our results indicate

Table 3. Numbers of $L$. paeta adults and nymphs in pyriproxyfen-treated arenas (individuals/arena \pm SE) $35 \mathrm{~d}$ after spraying

\begin{tabular}{lcc}
\hline \multicolumn{1}{c}{ Treatment } & Adults & Nymphs \\
\hline Without psocids, without kernels & $4.1 \pm 1.2 \mathrm{a}$ & $0.0 \pm 0.0 \mathrm{a}$ \\
Without psocids, with kernels & $1.1 \pm 0.6 \mathrm{bc}$ & $0.0 \pm 0.0 \mathrm{a}$ \\
With psocids, without kernels & $0.0 \pm 0.0 \mathrm{c}$ & $0.0 \pm 0.0 \mathrm{a}$ \\
With psocids, with kernels & $1.9 \pm 0.6 \mathrm{ab}$ & $3.7 \pm 2.5 \mathrm{a}$ \\
$F$ & 6.2 & 2.3 \\
$P$ & $<0.01$ & 0.10 \\
\hline
\end{tabular}

Within each column, means followed by the same letter are not significantly different ( $\mathrm{df}=3,32$; HSD test at 0.05 ; "without" or "with" indicate absence or presence during spraying, respectively).
Table 4. Numbers of $L$. bostrychophila adults and nymphs in pyriproxyfen-treated arenas (individuals/arena \pm SE) 35 d after spraying

\begin{tabular}{lcc}
\hline \multicolumn{1}{c}{ Treatment } & Adults & Nymphs \\
\hline Without psocids, without kernels & $2.0 \pm 0.8 \mathrm{a}$ & $30.0 \pm 10.5 \mathrm{a}$ \\
Without psocids, with kernels & $0.0 \pm 0.0 \mathrm{~b}$ & $3.4 \pm 3.0 \mathrm{bc}$ \\
With psocids, without kernels & $0.0 \pm 0.0 \mathrm{~b}$ & $0.1 \pm 0.1 \mathrm{c}$ \\
With psocids, with kernels & $0.4 \pm 0.4 \mathrm{ab}$ & $10.7 \pm 7.7 \mathrm{ab}$ \\
$F$ & 4.3 & 3.0 \\
$P$ & 0.01 & 0.04 \\
\hline
\end{tabular}

Within each column, means followed by the same letter are not significantly different ( $\mathrm{df}=3,32$; HSD test at 0.05 ; "without" or "with" indicate absence or presence during spraying, respectively).

that pyriproxyfen can reduce numbers of psocids on concrete but that the level of reduction is mainly dependent on the target species. There have been several studies on another IGR, methoprene, for control of psocids. In a recent study, Athanassiou et al. (2010b) found that methoprene was not able to control the psocids L. decolor, L. bostrychophila, Liposcelis entomophila (Enderlein), and L. paeta on maize (Zea mays L.), rice (Oryza sativa L.), and wheat (Triticum aestivum L.). Also, the combination of methoprene with spinosad was not effective for control of L. bostrychophila on wheat (Athanassiou et al. 2010a). These studies and earlier studies indicate lack of efficacy of methoprene for control of Liposcelis spp. (Nayak et al. 1998, 2002b). Bucci (1994) reported that L. bostrychophila was extremely tolerant to the IGR fenoxycarb, even at very high doses. These studies and our current findings indicate that psocids generally are quite tolerant to IGRs, including pyriproxyfen, although pyriproxifen is the most effective of IGRs evaluated thus far.

Access to food can moderate the efficacy of a given insecticide (Arthur 1998, 2009; Arthur et al. 2009). Arthur (2009) noted that survival of T. castaneum adults on concrete treated with chlorfenapyr increased when flour was present. Consequently, sanitation (presence or absence of food material) is an important variable that should be incorporated into evaluation of insecticides for stored-product pests. In previous studies, food was usually added after the application of the insecticide; thus, food was not treated. This may have allowed insects to moderate the toxic effects of the insecticides through feeding on untreated food. In our study, both cases were examined: insecticide-treated and insecticide-free food. There were no general trends in survival for either of food categories for all three species. We hypothesize that the presence of cracked kernels in all dishes might have reduced pyriproxyfen efficacy, although treatments without kernels were not evaluated in this study. These results suggest that removal of insecticide-treated food residues in a milling or warehouse facility may be just as important for pest control as removal of untreated food residues.

Differences among psocid species in their susceptibility to insecticides applied on concrete is an additional parameter that should be taken into consider- 
ation when evaluating insecticides. Among the species tested here, $L$. paeta is considered to be tolerant to several insecticides, such as chlorpyriphos-methyl, pirimiphos-methyl, and fenitrothion, whereas $L$. bostrychophila is considered susceptible (Collins et al. 2000, Nayak et al. 2002a). In our study, there were considerably greater numbers of $L$. bostrychophila nymphs, in both treated and untreated dishes, in comparison with the other two species. For example, the number of $L$. bostrychophila nymphs was 13 and 7 times higher than the numbers of $L$. paeta and $L$. decolor nymphs, respectively. In contrast with the other two species, L. bostrychophila typically reproduces parthenogenetically, with high potential for production of progeny (Wang et al. 2000). Athanassiou et al. (2010c) found that L. bostrychophila adult females generally produced considerably more F1 progeny than $L$. paeta or $L$. decolor in a wide variety of grain commodities. Even in insecticide-treated wheat and rice, Athanassiou et al. (2009) reported that $L$. bostrychophila produced greater numbers of offspring than L. paeta. Greater capacity for progeny production may counteract the insecticidal effect, especially in the case of IGRs, where this effect is primarily focused on the immature life stages. Nevertheless, pyriproxyfen reduced $L$. bostrychophila numbers in comparison with the control, but the level of reduction varied according to the treatment. In a previous study on wheat, rice, and maize, methoprene did not effectively control L. bostrychophila, L. decolor, or $L$. paeta, although that progeny production was reduced for all species.

Few adults of any species were found at the end of the 35-d exposure interval. It is well documented that $35 \mathrm{~d}$ is a sufficient interval for young psocid nymphs to reach the adult stage at the conditions examined here (Rees and Walker 1990, Leong and Ho 1995, Wang et al. 2000, Opit and Throne 2008). Therefore, we can conclude that there is an effect of pyriproxyfen on the species tested. This was evident even in the case of $L$. bostrychophila where the greatest number of nymphs was recorded on the treated substrates, yet the lowest number of adults was found. The exposure interval was selected to examine whether the exposed nymphs would reach the adult stage and the capacity of these adults for progeny production. However, we do not know whether the nymphs found on the pyriproxyfentreated surfaces had been arrested at that stage and were unable to become adults. For Plodia interpunctella (Hübner) (Lepidoptera: Pyralidae), Mohandass et al. (2006) found that hydroprene prolonged immature development or caused molting failure. Arthur et al. (2009) found that pyriproxyfen reduced adult emergence of the cigarette beetle, Lasioderma serricorne (F.) (Coleoptera: Anobiidae); the confused flour beetle, Tribolium confusum Jacquelin du Val (Coleoptera: Tenebrionidae); the sawtoothed grain beetle, Oryzaephilus surinamensis (L.) (Coleoptera: Silvanidae); T. castaneum; and P. interpunctella after $56 \mathrm{~d}$ of exposure, whereas, at the same conditions, hydroprene lost its effectiveness after $28 \mathrm{~d}$. Testing longer exposure intervals would indicate whether the activity of pyriproxyfen can gradually eliminate the psocid population.

In conclusion, pyriproxyfen showed activity against L. decolor, L. paeta, and L. bostrychophila on concrete, a characteristic that should be further evaluated to determine whether pyriproxyfen can eliminate psocid populations over time. In addition, the combined application of pyriproxyfen with a reduced-risk contact neurotoxic insecticide, such as chlorfenapyr (Guedes et al. 2008, Arthur 2009), may further increase its efficacy.

\section{Acknowledgments}

We thank Ann Redmon and Ngunza Kisangani for technical assistance, MGK for the pyriproxyfen sample, and Manoj Nayak for comments on an earlier version of this manuscript.

\section{References Cited}

Arthur,F. H. 1998. Effects of food source on red flour beetle (Coleoptera: Tenebrionidae) survival after exposure on concrete treated with cyfluthrin. J. Econ. Entomol. 91: $773-778$.

Arthur, F. H. 2009. Efficacy of chlorfenapyr against adult Tribolium castaneum exposed on concrete: effects of exposure interval, concentration and the presence of a food source after exposure. Insect Sci. 16: 157-163.

Arthur, F. H., S. Liu, B. Zhao, and T. W. Phillips. 2009. Residual efficacy of pyriproxyfen and hydroprene applied to wood, metal and concrete for control of stored product insects. Pest Manag. Sci. 65: 791-797.

Athanassiou, C. G., F. H. Arthur, and J. E. Throne. 2009. Efficacy of grain protectants against four psocid species on maize, rice and wheat. Pest Manag. Sci. 65: 1140-1146.

Athanassiou, C. G., F. H. Arthur, N. G. Kavallieratos, and J. E. Throne. 2010a. Efficacy of spinosad and methoprene, applied alone or in combination, against six stored-product insect species. J. Pest Sci. 84: 61-67.

Athanassiou, C. G., F. H. Arthur, and J. E. Throne. 2010b. Efficacy of methoprene for control of five species of psocids (Psocoptera) on wheat, rice, and maize. J. Food Prot. 73: 2244-2249.

Athanassiou, C. G., G. P. Opit, and J. E. Throne. 2010c. Influence of commodity type, percentage of cracked kernels, and wheat class on population growth of storedproduct psocids (Psocoptera: Liposcelidae). J. Econ. Entomol. 103: 985-990.

Bucci, R. 1994. Effects of two insect growth regulators on the booklouse Liposcelis bostrychophila. J. Stored Prod. Res. 30: 157-161.

Collins, P. J., M. K. Nayak, and R. Kopittke. 2000. Residual efficacy of four organophosphate insecticides on concrete and galvanized steel against three liposcelid psocid species (Psocoptera: Liposcelidae) infesting stored products. J. Econ. Entomol. 93: 1357-1363.

Guedes, R.N.C., J. F. Campbell, F. H. Arthur, G. P. Opit, K. Y. Zhu, and J. E. Throne. 2008. Acute lethal and behavioral sublethal responses of two stored-product psocids to surface insecticides. Pest Manag. Sci. 64: 1314-1322.

Hubert, J., V. Stejskal, Z. Munzbergova, J. Hajslova, and F. H. Arthur. 2007. Toxicity and efficacy of selected pesticides and new acaricides to stored product mites (Acari: Acaridida). Exp. Appl. Acarol. 42: 283-290. 
Kostyukovsky, M., B. Chen, S. Atsmi, and E. Shaaya. 2000. Biological activity of two juvenoids and two ecdysteroids against three stored product insects. Insect Biochem. Mol. Biol. 30: 891-897.

Leong, E.C.W., and S. H. Ho. 1995. Life cycle of Liposcelis entomophila (Psocoptera: Liposcelididae) and a culturing regime for liposcelidids. Bull. Entomol. Res. 85: 501-506.

Mockford, E. L., and P. D. Krushelnycky. 2008. New species and records of Liposcelis Motschulsky (Psocoptera: Liposcelididae) from Hawaii with first description of the male of Liposcelis bostrychophila Badonnel. Zootaxa 1766: 53-68.

Mohandass, S., F. H. Arthur, K. Y. Zhu, and J. E. Throne. 2006. Hydroprene prolongs developmental time and increases mortality in wandering-phase Indianmeal moth (Lepidoptera: Pyralidae) larvae. J. Econ. Entomol. 99: 1509-1519.

Nayak, M. K. 2006. Psocid and mite pests of stored commodities: small but formidable enemies, pp. 1061-1073. In I. Lorini, B. Bacaltchuk, H. Beckel, D. Deckers, E. Sundfeld, J. P. dos Santos, J. D. Biagi, J. C. Celaro, L. R. D’A. Faroni, L. de O. F. Bortolini et al. (eds.), Proceedings of the 9th International Working Conference on Stored-Product Protection, 15-18 October 2006, Campinas, Sao Paulo, Brazil. Brazilian Post-harvest Association-ABRAPOS, Passo Fundo, RS, Brazil.

Nayak, M. K., P. J. Collins, and R. S. Reid. 1998. Efficacy of grain protectants and phosphine against Liposcelis bostrychophila, L. entomophila and L. paeta (Psocoptera: Liposcelidae). J. Econ. Entomol. 91: 1208-1212.

Nayak, M. K., P. J. Collins, and R. A. Kopittke. 2002a. Comparative residual toxicities of carbaryl, deltamethrin and permethrin as structural treatments against three liposcelidid psocid species (Psocoptera: Liposcelididae) infesting stored commodities. J. Stored Prod. Res. 38: 247258.

Nayak, M. K., P. J. Collins, and H. Pavic. 2002b. Long-term effectiveness of grain protectants and structural treatments against Liposcelis decolor (Pearman) (Psocoptera:
Liposcelididae), a pest of stored products. Pest Manag. Sci 58: 1223-1228.

Nayak, M. K., P. J. Collins, and R. A. Kopittke. 2003. Residual toxicities and persistence of organophosphorus insecticides mixed with carbaryl as structural treatments against three liposcelidid psocid species (Psocoptera: Liposcelididae) infesting stored grain. J. Stored Prod. Res. 39: 343-353.

Nayak, M. K., G. J. Daglish, and V. S. Byrne. 2005. Effectiveness of spinosad as a grain protectant against resistant beetle and psocid pests of stored grain in Australia. J. Stored Prod. Res. 41: 455-467.

Opit, G. P., and J. E. Throne. 2008. Population growth and development of psocid Lepinotus reticulatus at constant temperatures and relative humidities. J. Econ. Entomol. 101: 605-615.

Rees, D. P., and A. J. Walker. 1990. The effect of temperature and relative humidity on population growth of three Liposcelis species infesting stored products in tropical countries. Bull. Entomol. Res. 80: 353-358.

Sall, J. E., A. Lehman, and L. Creighton. 2001. JMP Start Statistics. A guide to statistics and data analysis using JMP and JMP IN software. Duxbury Press, Belmont, CA.

Sokal, R. R., and F. J. Rohlf. 1995. Biometry, 3rd ed. W. H. Freeman and Company, New York.

Throne, J. E., G. P. Opit, and P. W. Flinn. 2006. Seasonal distribution of psocids in stored wheat, pp. 1095-1103. In I. Lorini, B. Bacaltchuk, H. Beckel, D. Deckers, E. Sundfeld, J. P. dos Santos, J. D. Biagi, J. C. Celaro, L. R. D’A. Faroni, L. de O. F. Bortolini, et al. (eds.), Proceedings of the 9th International Working Conference on Stored-Product Protection, 15-18 October 2006, Campinas, Sao Paulo, Brazil. Brazilian Post-harvest Association-ABRAPOS, Passo Fundo, RS, Brazil.

Wang, J. J., J. H. Tsai, Z. H. Zhao, and L. S. Li. 2000. Development and reproduction of the psocid Liposcelis bostrychophila (Psocoptera: Liposcelididae) as a function of temperature. Ann. Entomol. Soc. Am. 93: 261-270.

Received 20 November 2010; accepted 30 April 2011. 